INTERNATIONAL JOURNAL
OHARMACEUTICAL SCIENCES
RESEARCH
RESEI

Received on 31 December, 2012; received in revised form, 28 January, 2013; accepted, 18 March, 2013

\title{
FORMULATION AND EVALUATION OF FAST DISSOLVING TABLETS OF TELMISARTAN
}

\author{
Kapil Chauhan*, Bharat Parashar, Abhishek Chandel and Varun Thakur
}

Department of Pharmaceutics, Manav Bharti University, Village Laddo, Tehsil \& Distt. Solan- 173229, Himachal Pradesh, India

Keywords:

Telmisartan, Fast Dissolving, Disintegration, Anti-hypertensive

Correspondence to Author:

Kapil Chauhan

Department of Pharmaceutics, Manav Bharti University, Village Laddo, Tehsil \& Distt. Solan- 173229,

Himachal Pradesh, India

E-mail: chauhankapil058@gmail.com

\begin{tabular}{|c|c|}
\hline \multirow{3}{*}{ 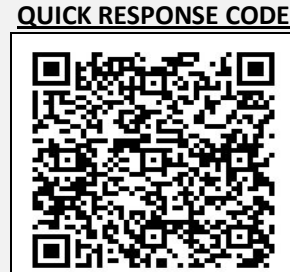 } & \\
\hline & ICV $(20$ \\
\hline & $\begin{array}{l}\text { Article can be } \\
\text { accessed online on: } \\
\text { www.ijpsr.com }\end{array}$ \\
\hline
\end{tabular}

ABSTRACT: The patients with sudden increase blood pressure have markedly reduced function ability and extremely restless, in such cases rapid onset of action is of prime importance. So the patients would be benefited from acute treatment by using Fast dissolving drug delivery system. Telmisartan is an Anti-hypertensive drug which is insoluble in water; hence the drug may be slowly or incompletely dissolves in the gastro-intestinal tract. So the rate of dissolution and therefore its bioavailability is less (bioavailability 42\%). In the present study an attempt has been made to prepare. Fast Dissolving tablets of Telmisartan by using Superdisintegrants- Crosscarmellose Sodium, Doshion ,Sodium Starch Glycolate, level of addition to increase the rate of drug release from dosage form to increase the dissolution rate and hence its bioavailability. The tablets were prepared by Direct Compression methods and the prepared blend and tablets were evaluated for their physicochemical properties and In-vitro dissolution study. The evaluation studies were performed such as Weight Variation, Thickness, Hardness, Disintegrating Time, Wetting Time, and In-vitro Drug Release and Stability Study. The Disintegration time of Fast Dissolving tablets were increased by the addition of concentration of Superdisintegrants.
INTRODUCTION: Oral drug administration has been one of the most suitable and widely accepted by the patients for the delivery of most therapeutically active drugs. Various dosage forms like tablets, capsules and liquid preparations have been administered by oral route. But, due to some unsuitable physiological conditions of the gastrointestinal tract like relatively poor absorption, presence of various digestive enzymes of the gastrointestinal lumen and epithelium, poor absorption efflux (i.e. by P-glycoprotein, etc.) and first pass metabolism by hepatic enzymes, the administration of some drugs is affected. Also, it limits many drugs to reach into the therapeutic level. Hence, to minimize the problems associated with drugabsorption through gastro-intestinal membrane, researchers have been developing intraoral drug delivery systems that will enhance the therapeutic drug level, avoids first-pass and gut-wall metabolism, increases the bioavailability of active medicament or improve convenience of dosing. The target sites for local drug delivery in the oral cavity include the following: buccal, sublingual, periodontal region, tongue and gum ${ }^{1}$. Other desirable targeting sites adjacent to oral cavity include pharynx, larynx, adenoids and tonsils ${ }^{2}$.

Within the oral cavity, delivery of drugs via the membranes of the oral cavity is classified into three categories:

i) Sublingual delivery, which is systemic delivery of drugs through the mucosal membranes lining 
the floor of the mouth to the systemic circulation;

ii) Buccal delivery, which is drug administration through the mucosal membranes lining the cheeks and the area between the gums and upper and lower lips to the systemic circulation;

iii) Local delivery, which is drug delivery to periodontal, gingival, and odontal delivery for the local treatment of aphthous ulcers, bacterial and fungal infections and periodontal disease.

Fast Dissolving Tablet: Recent advances in novel drug delivery system aims to enhance safety and efficacy of drug molecule by formulating a convenient dosage form for administration and to achieve better patient compliance ${ }^{3}$. One such approach is "fast disintegrating tablets".

The oral route remains the perfect route for the administration of therapeutic agents because the low cost of therapy, manufacturing and ease of administration lead to high levels of patient compliance. Many patients have difficulty swallowing tablets and hard gelatin capsules and consequently do not take medications as prescribed ${ }^{4}$.

It is estimated that $50 \%$ of the population is affected by this problem, which results in a high incidence of noncompliance and ineffective therapy. The demand for solid dosage forms that can be dissolved and suspended in water, chewed, or rapidly dissolved in the mouth is particularly strong in the pediatric and geriatric markets, with further application to other patients who prefer the convenience of a readily administered dosage form.

Less frequently, they are designed to be absorbed through the buccal and esophageal mucosa as the saliva passed into the stomach. In the latter case, the bioavailability of a drug from fast dispersing formulations may be even greater than that observed for standard dosage forms 5 .

A fast dissolving tablet can be defined as a solid dosage form that can disintegrates into smaller granules which slowly dissolve in the mouth. The disintegration time for fast dissolving tablet varies from a few seconds to more than a minute depending on the formulation and the size of the tablet.
A fast disintegrating or dissolving system or tablet can be defined as a solid dosage form that can disintegrate or dissolve within 30 seconds, in the oral cavity resulting in a solution or suspension without administration of water.

The fast disintegrating tablets are synonymous with fast dissolving tablets; melt in mouth tablets, rapimelts, Porous tablets, Orodispersible, quick dissolving or rapidly disintegrating tablets. Their growing importance was underlined recently when European pharmacopoeia adopted the term "Orodispersible tablet" as a tablet that to be placed in the mouth where it disperses rapidly, before swallowing significance of this drug delivery system includes administration without water, accuracy dosage, easy portability, alternative to liquid dosage forms ideal for pediatrics' \& geriatric patients and rapid onset of action ${ }^{6}$.

MATERIALS: Telmisartan was a gift sample obtained from Lupin Pharma. Microcrystalline cellulose, Ac-Di-Sol, Doshion, Primogel, Menthol and Magnesium stearate were provided by SDFCL. Sodium lauryl sulphate was obtained from NICE Chemicals and mannitol from SPB Pharma, Solan. All the chemicals and solvents were of analytical grade.

FORMULATION: Telmisartan Fast Dissolving tablet is prepared by direct compression method using various Disintegrants used like Crosscarmellose Sodium, Methacrylic copolymer with divinyl benzene, Sodium Starch Glycolate. Mannitol, Microcrystalline Cellulose and Menthol flavor was co-sifted through mesh No-60.

Passed and retained Mannitol and Microcrystalline cellulose keep separately. Telmisartan was geometrically sifted with mesh No. 60 passed Mannitol and Microcrystalline cellulose. Step "B" material was co-sifted along with retained Mannitol; Microcrystalline Cellulose of each ingredients was taken for each specified formulation through mesh No- 40.

Magnesium Stearate passed through mesh No- 60, and lubricates the material. The resulting lubricated material was compressed into tablet with $6 \mathrm{~mm}$ punches $^{7}$ (table 1). 
TABLE 1: COMPOSITION OF FAST DISSOLVING TABLETS

\begin{tabular}{|c|c|c|c|c|c|c|c|c|c|c|}
\hline S. No. & Ingredient & F1 & $\mathbf{F} 2$ & F3 & $\mathbf{F 4}$ & F5 & F6 & F7 & F8 & F9 \\
\hline 1. & Telmisartan & 10 & 10 & 10 & 10 & 10 & 10 & 10 & 10 & 10 \\
\hline 2. & $\begin{array}{l}\text { Microcrystalline } \\
\text { cellulose }\end{array}$ & 50 & 50 & 50 & 50 & 50 & 50 & 50 & 50 & 50 \\
\hline 3. & $\begin{array}{l}\text { Croscarmellose } \\
\text { Sodium }\end{array}$ & 2.5 & 3.75 & 5 & & & & & & \\
\hline 4. & Doshion & & & & 2.5 & 3.75 & 5 & & & \\
\hline 5. & $\begin{array}{l}\text { Sodium starch } \\
\text { Glycolate }\end{array}$ & & & & & & & 2.5 & 3.75 & 5 \\
\hline 6. & $\begin{array}{l}\text { Sodium lauryl } \\
\text { sulphate }\end{array}$ & 1 & 1 & 1 & 1 & 1 & 1 & 1 & 1 & 1 \\
\hline 7. & Menthol & 2 & 2 & 2 & 2 & 2 & 2 & 2 & 2 & 2 \\
\hline 8. & Magnesium Stearate & 3 & 3 & 3 & 3 & 3 & 3 & 3 & 3 & 3 \\
\hline 9. & Mannitol Total up to & 100 & 100 & 100 & 100 & 100 & 100 & 100 & 100 & 100 \\
\hline
\end{tabular}

Evaluation of Formulated Tablets: Firstly the precompression parameters like Angle of repose, Bulk density and Tap density, Powder Compressibility (Carr's compressibility index), Hausner's ratio and Particle Size Distribution were determined.

\section{Post-compression parameters:}

1. General appearance: The general appearance of tablets, its visual identity and overall 'elegance' is essential for consumer acceptance, control of lot-to-lot uniformity and general tablet-to-tablet uniformity and for monitoring the production process. The control of general appearance involves measurement of attributes such as a tablet's size, shape, color, presence or absence of odor, taste, surface textures, physical flaws and consistency.

2. Uniformity of thickness: The thickness of individual tablets may be measured with a micrometer, which permits accurate measurements and provides information of the variation between tablets. Tablet thickness should be controlled within a $\pm 5 \%$ variation of a standard value. Any variation in thickness within a particular lot of tablets or between manufacturer's lots should not be apparent to the unaided eye for consumer acceptance of the product. In addition, thickness must be controlled to facilitate packaging. The physical dimensions of the tablet along with the density of the material in the tablet formulation and their proportions, determine the weight of the tablet ${ }^{8}$. The size and shape of the tablet can also influence the choice of tablet machine to use, the best particle size for granulation, production lot size that can be made, the best type of tableting processing that can be used, packaging operations, and the cost of production.

3. Hardness: The resistance of tablets to capping, abrasion or breakage under conditions of storage, transportation and handling before usage depends on its hardness. It is now designated as either the Monsanto or Stokes hardness tester. The instrument measures the force required to break the tablet when the force generated by a coil spring is applied diametrically to the tablet.

Hardness, which is now more appropriately called crushing strength determinations are made during tablet production and are used to determine the need for pressure adjustment on tablet machine. If the tablet is too hard, it may not disintegrate in the required period of time to meet the dissolution specifications; if it is too soft, it may not be able to withstand the handling during subsequent processing such as coating or packaging and shipping operations.

The force required to break the tablet is measured in kilograms and a crushing strength of $4 \mathrm{Kg}$ is usually considered to be the minimum for satisfactory tablets. Oral tablets normally have a hardness of 4 to $10 \mathrm{~kg}$; however, hypodermic and chewable tablets are usually much softer $(3 \mathrm{~kg})$ and some sustained release tablets are much harder $(10-20 \mathrm{~kg})$. 
Tablet hardness has been associated with other tablet properties such as density and porosity. Hardness generally increases with normal storage of tablets and depends on the shape, chemical properties, binding agent and pressure applied during compression.

A significant strength of ODT is difficult to achieve due to the specialized processes and ingredients used in the manufacturing. The limit of hardness for the ODT is usually kept in a lower range to facilitate early disintegration in the mouth. The hardness of the tablet may be measured using conventional hardness testers. Three tablets were randomly picked from each formulation and the mean and standard deviation values were calculated.

4. Friability (F): Friability of the tablet determined using Roche friabiltor. This device subjects the tablet to the combined effect of abrasion and shock in a plastic chamber revolving at $25 \mathrm{rpm}$ and dropping a tablet at 1 height of 6 inches in each revolution. Preweighted sample of tablets was placed in the friabilator and were subjected to the 100 revolutions. Tablets were de-dusted using a soft muslin cloth and reweighed. The friability $(F)$ is given by the formula.

$$
\mathrm{F}=\mathrm{W}_{\text {initial }}-\mathrm{W}_{\text {final } \times} 100 / \mathrm{W}_{\text {final }}
$$

$\%$ Friability of tablets less than $1 \%$ is considered acceptable. Thus, it is necessary that this parameter should be evaluated and the results are within bound limits $(0.1-0.9 \%)$.

5. Weight Variation Test: The weight variation test of the tablets was done as per the guidelines of Indian Pharmacopoeia. Ten tablets from each batch were weighed in digital balance and average weight was determined and standard deviation was calculated. The USP has provided limits for the average weight of uncoated compressed tablets. These are applicable when the tablet contains $50 \mathrm{mg}$ or more of the drug substance or when the latter comprises $50 \%$ or more, by weight of the dosage form. Twenty tablets are weighed individually and the average weight is calculated. The individual tablet weights are then compared to the average weight. Not more than two of the tablets must differ from the average weight to the not more than the percentages stated in Table. No tablet must differ by more than double the relevant percentage. In all the formulations the tablet weight was more than $130 \mathrm{mg}$ and less than 324 $\mathrm{mg}$, hence $7.5 \%$ maximum difference allowed.

The results obtained were shown in Table 2.

TABLE 2: STANDARD PERCENTAGE DEVIATION IN WEIGHT

\begin{tabular}{cc}
\hline Average Weight of a tablet & Percentage deviation \\
\hline 130mg or less & 10 \\
More than $130 \mathrm{mg}$ through $324 \mathrm{mg}$ & 7.5 \\
More than $324 \mathrm{mg}$ & 5 \\
\hline
\end{tabular}

6. Wetting time: Wetting time is closely related to the inner structure of the tablets and to the hydrophilicity of the excipient. According to the following equation proposed by Washburn E.W (1921), the water penetration rate into the powder bed is proportional to the pore radius and is affected by the hydrophilicity of the powders.

$$
\mathrm{dl} / \mathrm{dt}=\mathrm{r} \gamma \cos \theta /(4 \theta 1)
$$

Where 1 is the length of penetration, $r$ is the capillary radius, $\gamma$ is the surface tension, $\theta$ is the liquid viscosity, $\mathrm{t}$ is the time, and $\theta$ is the contact angle. It is obvious that pores size becomes smaller and wetting time increases with an increase in compression force or a decrease in porosity. A linear relationship exists between wetting time and disintegration time. Thus wetting is the important step for disintegration process to take place ${ }^{9}$.

A piece of tissue paper folded double was placed in a Petri dish (internal diameter is $6.5 \mathrm{~cm}$ ) containing $6 \mathrm{ml}$ of water. The tablet was placed on the paper, and the time for complete wetting of the tablet was measured in seconds. The method was slightly modified by maintaining water at $37^{\circ} \mathrm{C}$. Wetting time corresponds to the time taken for the tablet to disintegrate when kept motionless on the tongue.

7. Water absorption Ratio: A piece of tissue paper folded twice was placed in a small Petri dish containing $6 \mathrm{ml}$ of water. A tablet was put on the paper $\&$ the time required for complete wetting was measured. The wetted tablet was then weighed. Water absorption ratio, $\mathrm{R}$, was determined using following equation; 


$$
\mathrm{R}=10(\mathrm{Wa} / \mathrm{Wb})
$$

Where, $\mathrm{Wb}$ is weight of tablet before water absorption \& $\mathrm{Wa}$ is weight of tablet after water absorption.

8. In vitro Disintegration time: The in-vitro disintegration time was determined using disintegration test apparatus. One tablet was placed in each of the six tubes of the apparatus and one disc was added to each tube. The time in seconds taken for complete disintegration of the tablet with no palatable mass remaining in the apparatus was measured in seconds. I.P. Specifications: Place one tablet in each of the 6 tubes of the basket. Add a disc to each tube and run the apparatus using $\mathrm{pH} 6.8$ (simulated saliva fluid) 58 maintained at $37^{\circ} \pm 2^{\circ} \mathrm{C}$ as the immersion liquid. The assembly should be raised and lowered between 30 cycles per minute in the $\mathrm{pH} 6.8$ maintained at $37^{\circ} \pm 2^{\circ} \mathrm{C}$. The time in seconds taken for complete disintegration of the tablet with no palpable mass remaining in the apparatus was measured and recorded.

9. In vitro dispersion time: Tablet was added to $10 \mathrm{ml}$ of $0.1 \mathrm{~N} \mathrm{HCL}$ at $37+-0.5^{\circ} \mathrm{C}$. Time required for complete dispersion of tablet was measured.

Assay: Twenty tablets from each batch were weighed accurately and powdered. Weight the quantity of the powder equivalent to $100 \mathrm{mg}$ Telmisartan, was shaken with $100 \mathrm{ml}$ of $0.1 \mathrm{~N}$ Hydrochloric acid in $100 \mathrm{ml}$ volumetric flask, and from this $10 \mathrm{ml}$ was pipette out and then dilute up to $100 \mathrm{ml}$. From standard solution again $10 \mathrm{ml}$ pipette out and diluted up to $100 \mathrm{ml}$ in $100 \mathrm{ml}$ volumetric flask. Resulting solution was filtered and assayed at $292 \mathrm{~nm}$ and content of Telmisartan was calculated 0.1 NHCL as blank.

10. Drug content uniformity: Equivalent to $20 \mathrm{mg}$ of the drug was weighed accurately, dissolved in $0.1 \mathrm{~N}$ Sodium Hydroxide $(\mathrm{NaOH})$ and suitably diluted with phosphate buffer solution of $\mathrm{pH} 6.8$. The content of Telmisartan was determined spectrophotometrically at $292 \mathrm{~nm}$ against blank using UV-visible spectrophotometer (1800 Shimadzu).
Assay $=$

$\frac{A 1 \times}{A 2} \frac{\text { Std.wt }}{100} \times \frac{1}{100} \times \frac{100}{\text { Sample wt }} \times \frac{100}{1} \times \frac{P}{100} \times \frac{100}{L C} \times$

Avg.wt

Where, A1- Sample Absorbance; A2- Standard Absorbance; P- Potency of drug; LC- Label Claim

11. In vitro Dissolution studies: In-vitro dissolution studies for all the fabricated tablets of Telmisartan were carried out using USP apparatus type II at $50 \mathrm{rpm}$. The dissolution medium used was 6.8 phosphate buffer $(900 \mathrm{ml})$ maintained at $37 \pm 0.5^{\circ} \mathrm{C}$. Aliquots of dissolution media were withdrawn $(5 \mathrm{ml})$ at different intervals and content of Telmisartan was measured by determining absorbance at $296 \mathrm{~nm}$. $5 \mathrm{ml}$ aliquot was withdrawn at the $1 \mathrm{~min}, 2 \mathrm{~min}$ to be continued at the $1 \mathrm{~min}$. intervals and filtered by whatman filter paper, suitably diluted and analyzed at $296 \mathrm{~nm}$ using UV-Visible Spectrophotometer ${ }^{10}$. An equal volume of fresh medium, which was pre-warmed at $37^{\circ} \mathrm{C}$ was replaced in to the dissolution medium after each sampling to maintain the constant volume throughout the test. Absorbance was taken at $296 \mathrm{~nm}$ and percentage release was calculated. The results are listed in Table No.4 and the dissolution profile is shown in Fig. 1, 2 and 3.

RESULTS AND DISCUSSION: The present study was undertaken with an aim to formulate and evaluate Fast Dissolving tablets of Telmisartan using direct compression method with the addition of superdisintegranting agents. To increase the dissolution rate of poorly soluble drug Telmisartan, by using the addition of Ac-Di-Sol, Doshion and Primogel as Superdisintegrants at three different concentrations of $5 \%, 7.5 \%, 10 \%$.

Preformulation study was carried out initially and results directed for the further course of formulation. Solubility enhancement of Telmisartan was performed by the use surfactants (Sodium Lauryl Sulfate). Various formulations of Fast Dissolving tablets Telmisartan were formulated by using various superdisintegrants- Crosscarmellose Sodium, Doshion, Sodium Starch Glycolate. The tablets were evaluated for physical parameter such as Hardness, thickness, weight variation, friability, in-vitro disintegration, wetting time and in vitro Dissolution. 
Disintegration time of optimized formulation F9 was compared to other formulation, where it observed that disintegration time of F6 batch was $29 \mathrm{sec}$. The dissolution study was carried out in 6.8 phosphate buffer as a dissolution media the effect of surfactants on dissolution was studies on final formulation in which $1 \%$ SLS were added in to the tablet formulation. Stability study was carried out for the optimized formulation according to ICH guide lines at $2-8^{\circ} \mathrm{C}$ (controlled sample), room temperature and $40^{\circ} \mathrm{C} / 75 \% \mathrm{RH}$ for 1 month. Tablets were evaluated for assay, Disintegrating time, in-vitro drug release profile after one month. It concluded that Formulation F9 was stable. The results showed that there was no significant change in physical and chemical parameter of the tablet, hence the formulation was found to be stable. In the comparison, formulation with Doshion 10\% i.e., F9 the best results was found.

TABLE 3: PRE-COMPRESSION PARAMETERS OF TELMISARTAN POWDER BLEND

\begin{tabular}{cccccc}
\hline Batch code & Bulk density & Tapped density & Angle of repose & \% compressibility & Hausner ratio \\
\hline F1 & 0.517 & 0.612 & 31.25 & 15.52 & 1.184 \\
F2 & 0.524 & 0.621 & 32.12 & 15.62 & 1.185 \\
F3 & 0.509 & 0.611 & 31.24 & 16.69 & 1.200 \\
F4 & 0.514 & 0.611 & 32.75 & 15.88 & 1.189 \\
F5 & 0.519 & 0.624 & 33.75 & 16.82 & 1.202 \\
F6 & 0.517 & 0.612 & 33.10 & 15.52 & 1.183 \\
F7 & 0.527 & 0.620 & 29.45 & 15.00 & 1.176 \\
F8 & 0.521 & 0.619 & 28.78 & 15.83 & 1.208 \\
F9 & 0.515 & 0.618 & 30.10 & 16.66 & \\
\hline
\end{tabular}

TABLE 4: POST COMPRESSION PROPERTIES OF TELMISARTAN TABLETS

\begin{tabular}{ccccccc}
\hline $\begin{array}{c}\text { Batch } \\
\text { code }\end{array}$ & $\begin{array}{c}\text { Thickness } \\
(\mathbf{M M})\end{array}$ & $\begin{array}{c}\text { Weight } \\
\text { variation }\end{array}$ & $\begin{array}{c}\text { Hardness } \\
\left(\mathbf{k g} / \mathbf{c m}^{\mathbf{2}}\right)\end{array}$ & $\begin{array}{c}\text { Friability } \\
(\boldsymbol{\%})\end{array}$ & $\begin{array}{c}\text { In vitro disintegration } \\
\text { time (sec) }\end{array}$ & $\begin{array}{c}\text { Wetting } \\
\text { time }(\mathbf{s e c})\end{array}$ \\
\hline F1 & 3.40 & 98 & 2.50 & 0.60 & 41 & 59 \\
F2 & 3.42 & 100 & 2.30 & 0.65 & 37 & 53 \\
F3 & 3.41 & 99 & 2.40 & 0.65 & 32 & 46 \\
F4 & 3.42 & 102 & 2.50 & 0.70 & 35 & 53 \\
F5 & 3.43 & 100 & 2.40 & 0.65 & 31 & 46 \\
F6 & 3.41 & 98 & 2.30 & 0.55 & 29 & 39 \\
F7 & 3.42 & 97 & 2.50 & 0.65 & 48 & 61 \\
F8 & 3.42 & 102 & 2.40 & 0.50 & 43 & 58 \\
F9 & 3.41 & 100 & 2.50 & 0.60 & 38 & 53 \\
\hline
\end{tabular}

TABLE 5: IN VITRO DRUG RELEASE STUDY OF FORMULATED TABLETS

\begin{tabular}{ccccccccccc}
\hline & \multirow{8}{*}{ Sr. No. } & Time & \multicolumn{10}{c}{ \% of Drug Release } \\
\cline { 2 - 11 } & (in min) & F1 & F2 & F3 & F4 & F5 & F6 & F7 & F8 & F9 \\
\hline $\mathbf{1}$ & 0 & 0 & 0 & 0 & 0 & 0 & 0 & 0 & 0 & 0 \\
$\mathbf{2}$ & 1 & 36.72 & 37.48 & 41.80 & 45.72 & 48.73 & 49.86 & 38.25 & 35.59 & 32.98 \\
$\mathbf{3}$ & 2 & 65.81 & 66.58 & 71.46 & 73.55 & 76.36 & 79.74 & 69.01 & 63.73 & 58.09 \\
$\mathbf{4}$ & 3 & 84.53 & 86.25 & 90.98 & 91.78 & 93.30 & 95.57 & 89.64 & 81.90 & 75.88 \\
$\mathbf{5}$ & 4 & 87.07 & 89.70 & 92.25 & 93.41 & 94.35 & 96.46 & 91.08 & 84.97 & 79.67 \\
$\mathbf{6}$ & 5 & 88.49 & 91.54 & 93.12 & 94.98 & 95.28 & 97.17 & 92.15 & 86.74 & 81.23 \\
$\mathbf{7}$ & 6 & 89.52 & 92.22 & 94.49 & 95.34 & 95.98 & 97.92 & 92.99 & 88.34 & 81.86 \\
$\mathbf{8}$ & 7 & 90.59 & 92.90 & 94.67 & 96.08 & 96.68 & 98.64 & 93.72 & 89.58 & 82.84 \\
\hline
\end{tabular}




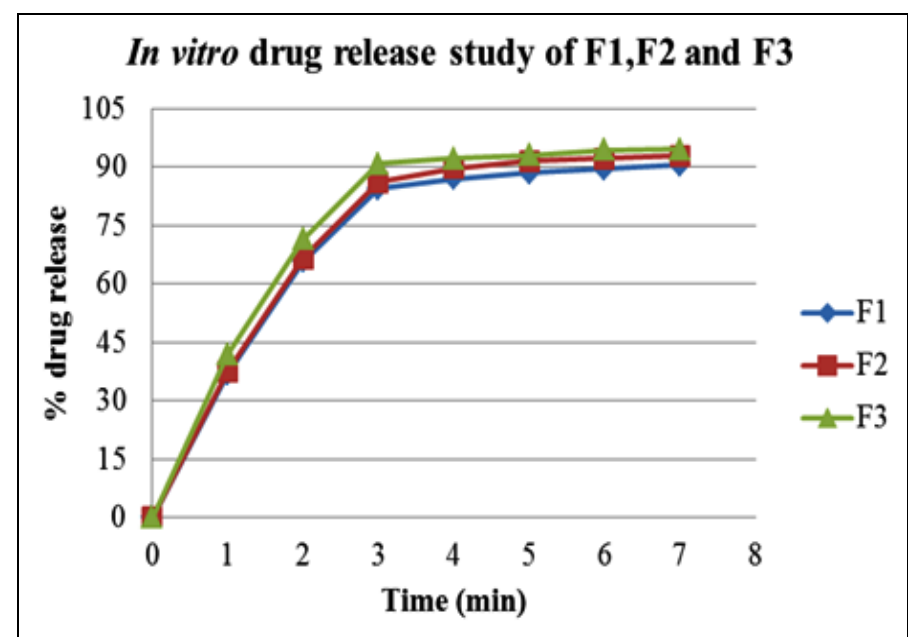

FIG. 1: IN VITRO DRUG RELEASE STUDY OF F1, F2 AND F3

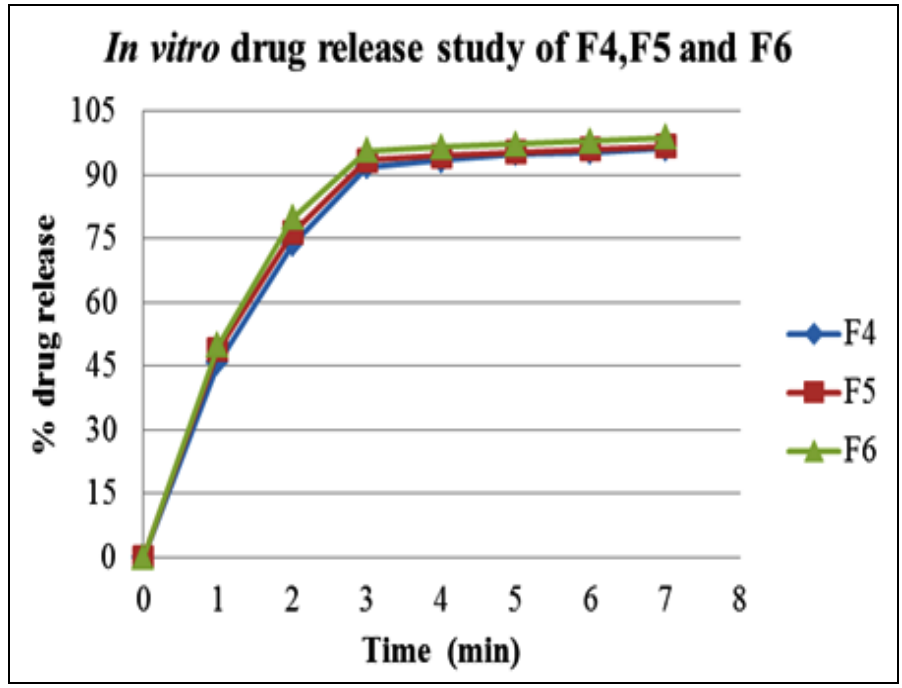

FIG. 2: IN VITRO DRUG RELEASE STUDY OF F4, F5 AND F6

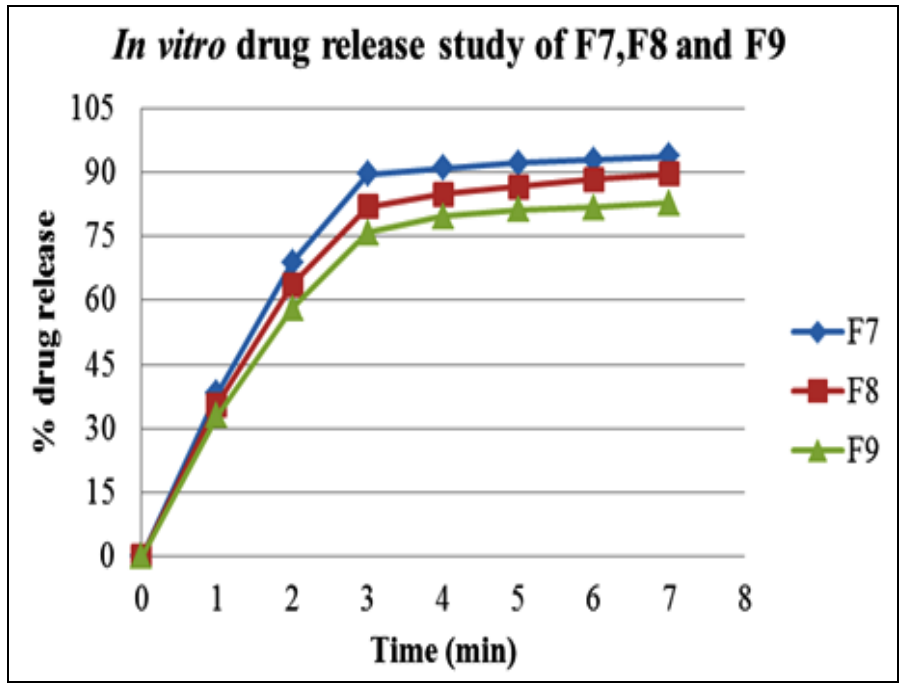

FIG. 3: IN VITRO DRUG RELEASE STUDY OF F7, F8 AND F9

How to cite this article:

Chauhan K, Parashar B, Chandel A and Thakur V: Formulation and evaluation of Fast Dissolving Tablets of Telmisartan. Int J Pharm Sci Res 2013; 4(4); 1514-1520. 